\title{
Mastocitoma cutâneo
} em cães: uma breve revisão

\section{Cutaneous mast cell tumor in dogs: a brief review}

\section{Resumo}

$\mathrm{Na}$ espécie canina, o mastocitoma é um dos tumores malignos mais diagnosticados, e a sua apresentação cutânea é de aproximadamente $11 \%$. O presente trabalho é uma revisão de literatura que trata do mastocitoma cutâneo canino, abordando aspectos de incidência, etiologia, apresentação clínica, estadiamento clínico, diagnóstico, modalidades de tratamento e prognósticos. Apesar dos avanços atuais observados no diagnóstico e tratamento desse tipo de tumor o estabelecimento do prognóstico é ainda muito incerto pois a sua apresentação clínica, comportamento biológico e resposta ao tratamento são bastante variáveis.

\section{Summary}

In dogs, mast cell tumor is one of the most frequent malignancies, whose cutaneous presentation achieve levels of $11 \%$. The present paper review the available literature of canine cutaneous mast cell tumor discussing it's incidence, etiology, clinical presentation, clinical stage, diagnosis, treatment and prognosis. In spite of the actual advances in the diagnosis and treatment, of this pathology it's prognosis is very uncertain because the clinical, biological behavior and treatment responses are so variable. 
Isadora Helena de Sousa Melo ${ }^{1}$ Geórgia Modé Magalhães ${ }^{2}$

Carlos Eduardo Fonseca Alves $^{3}$

Sabryna Gouveia Calazans ${ }^{4}$
Av. Dr. Armando Salles de Oliveira, 201

14404-600, Parque Universitário, Franca - SP, Brasil

工 +5516 37118713

凶isahelenasousa@yahoo.com.br

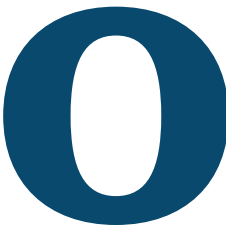

mastocitoma é um dos tumores cutâneos mais diagnosticados em cães. O presente trabalho é uma revisão de literatura que trata da incidência, etiologia, apresentação clínica, estadiamento clínico do tumor, diagnóstico, modalidades de tratamento e prognósticos.

\section{Incidência e etiologia}

$\mathrm{Na}$ espécie canina, o mastocitoma é um dos tumores malignos mais diagnosticados, com incidência de aproximadamente $20 \%$ (LONDON \& THAMM, 2013). Villamil et al. (2011) A sua apresentação cutânea representa cerca de $11 \%$ dos tumores cutâneos no cão. Os mastocitomas podem ocorrer em animais de qualquer faixa etária, mas acometem principalmente animais adultos, com a média de nove anos (LONDON \& THAMM, 2013). Algumas raças, como Boxer, Labrador, Golden Retrievers e Shar-pei Chinês, são acometidas com maior frequência (VILLAMIL et al., 2011).

Laufer-Amorim (2011) observou que as cadelas apresentavam mastocitomas menos agressivos, e Kiupel e colaboradores (2005) já haviam inferido que os cães machos apresentavam menos tempo de sobrevida. Dentro desse contexto, White et al. (2011), sugeriram a existência de influência hormonal no desenvolvimento do mastocitoma dos cães, já que as fêmeas castradas apresentaram maior risco de ocorrência da doença. 

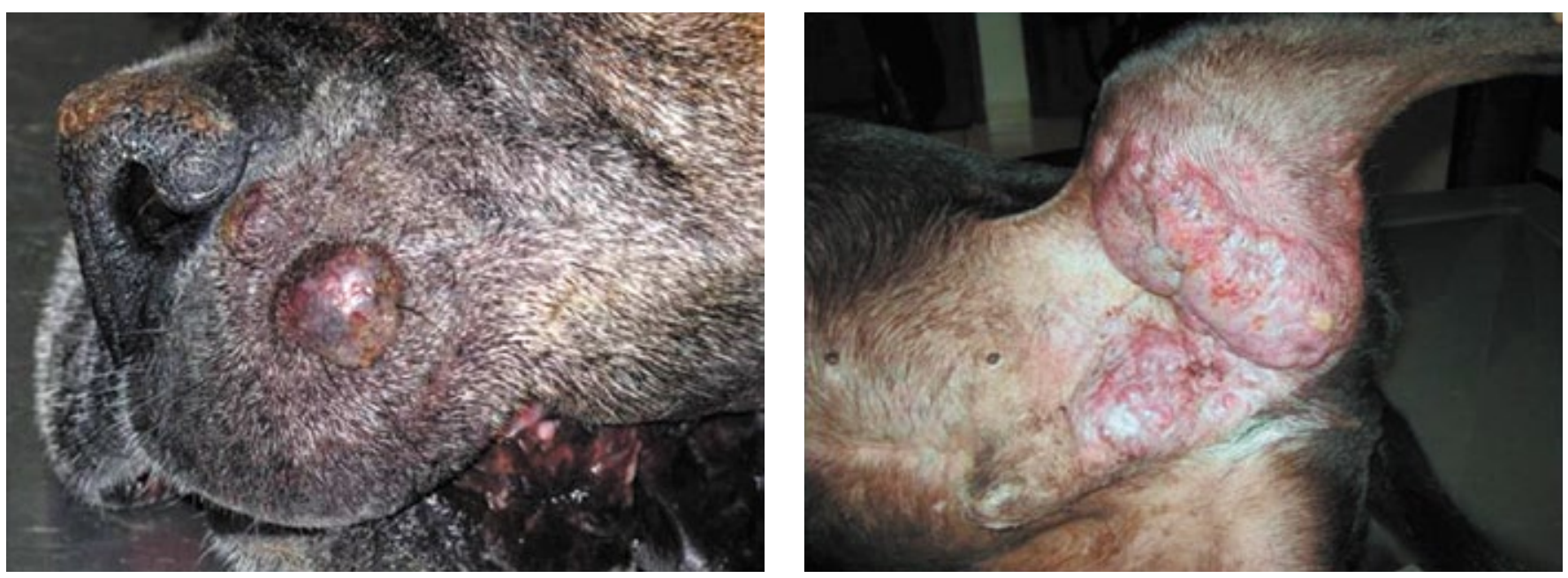

Figura 1 - Mastocitoma em focinho de um cão da raça Boxer (esquerda) e em região prepucial/inguinal, com envolvimento de membro pélvico em um cão sem raça definida (direita).

A etiologia dos mastocitomas não está comprovadamente definida, as hipótes aventadas incluem inflamação crônica, aplicação de substâncias irritantes na pele, infecção viral, alterações genéticas, porém, a verdadeira razão de sua elevada incidência ainda é desconhecida (DALECK et al., 2009). Todavia, o envolvimento do receptor de tirosina-quinase c-KIT na patogenia desta neoplasia já foi confirmado (ZEMKE et al., 2001).

\section{Apresentação clínica e estadiamento}

Mastocitomas ocorrem frequentemente na pele, principalmente na derme e tecido subcutâneo, enquanto mastocitomas extra-cutâneos são pouco observados (FURLANI et al., 2008; DALECK et al., 2009). Cães com mastocitoma cutâneo podem apresentar lesões múltiplas ou um tumor solitário. As lesões na derme são frequentemente bem circunscritas. A presença de ulceração e eritema é mais observada na apresentação dérmica, sendo que mastocitomas subcutâneos raramente provocam essas alterações. Contudo, em geral, os mastocitomas podem mimetizar qualquer lesão cutânea (DOBSON \& SCASE, 2007; MURPHY \& BREALEY, 2008) (Figura 1).

$\mathrm{Na}$ análise retrospectiva de 49 cães atendidos na Universidade Estadual Paulista - Campus de Jaboticabal, foi constatado que as localizações mais frequentes do mastocitoma cutâneo foram membros e as regiões escrotal, abdominal, inguinal, torácica e axilar Furlani e colaboradores (2008). (KIUPEL et al., 2005a; SFILIGOI et al., 2005) relataram que mastocitomas localizados nas regiões escrotal, prepucial e inguinal são os mais agressivos (Figura 1).

O comportamento biológico do mastocitoma é muito variável, há casos benignos que não comprometem o estado clínico do animal e outros extremamente malignos que podem provocar óbito (DALECK et al., 2009). A qualidade de vida de cães com mastocitoma pode ser comprometida pela manifestação de síndromes paraneoplásicas decorrentes da degranulação de mastócitos, seguida da liberação de histamina, heparina e enzimas proteolíticas. Em muitos casos, os pacientes apresentam gastrite ou úlcera gástrica, hipotensão e hemorragias (LONDON \& SEGUIN, 2003; LONDON \& THAMM, 2013).

O estadiamento clínico é muito importante para a determinação da extensão da doença e do estado geral do paciente (LONDON \& SEGUIN, 2003; LONDON \& THAMM, 2013). Para a sua determinação, além dos exames de imagem, é necessária a realização de exames citológicos e/ou histológicos dos órgãos com suspeita da ocorrência de metástases. Recomenda-se a realização dos exames: hemograma completo, perfil bioquímico e urinálise destinados a revelar a existência de possíveis síndromes paraneoplásicas (como anemia e hipereosinofilia) ou algumas comorbidades, tais como doenças infecciosas, renais e hepáticas. Nos casos de doença sistêmica avançada, o mielograma pode identificar a presença de mastócitos (LONDON \& SEGUIN, 2003).

O estadiamento clínico estabelecido pela Organização Mundial de Saúde (OMS) considera a localização do tumor primário e a presença de metástase à distância, (p. ex. linfonodos, fígado e baço) (LONDON \& THAMM, 2013) (Tabela 1).

\section{Diagnóstico}

Os mastocitomas são frequentemente diagnosticados pela citologia aspirativa com agulha fina (CAAF), pois os seus grânulos são de fácil visualização ao miscroscópio. Porém, nos tumores mais indiferenciados, a identificação dos mastócitos pode ser difícil (LAVALLE et al., 2003).

A despeito do diagnóstico de mastocitoma ter sido firmado pela CAAF, ainda se faz necessária a sua avaliação histológica, uma vez que o comportamento e prognóstico 
TABELA 1 - Estadiamento clínico do mastocitoma canino*

\begin{tabular}{ll} 
ESTÁDIO 0: & $\begin{array}{l}\text { Presença de um tumor incompletamente excisado } \\
\text { da derme, identificado histologicamente, sem } \\
\text { envolvimento de linfonodo regional. }\end{array}$ \\
\hline ESTÁDIO I: & $\begin{array}{l}\text { Presença de um tumor confinado à derme, sem } \\
\text { envolvimento de linfonodo regional. }\end{array}$ \\
\hline ESTÁDIO II: & $\begin{array}{l}\text { Presença de um tumor confinado à derme, com } \\
\text { envolvimento de linfonodos regionais. }\end{array}$ \\
\hline ESTÁDIO III: & $\begin{array}{l}\text { Tumores dérmicos múltiplos, tumores grandes e } \\
\text { infiltrativos com ou sem envolvimento de linfonodo } \\
\text { regional. }\end{array}$ \\
\hline ESTÁDIO IV: & $\begin{array}{l}\text { Qualquer tumor com metástase à distância, com } \\
\text { envolvimento de sangue ou medula óssea }\end{array}$ \\
*Os estádios I a III são classificados em subestádios 1(sem sinais sistêmicos) e 2 (com \\
sinais sistêmicos).
\end{tabular}

do tumor estão diretamente relacionados ao nível de graduação histológica.

Bostock (1973) desenvolveu um sistema que classificava os mastocitomas em três graus histológicos. Uma década depois, Patnaik et al. (1984) criaram outro esquema de classificação, também considerando três categorias: (1) bem diferenciado; (2) moderadamente diferenciado; e (3) pouco diferenciado, e que, até hoje, é o mais utilizado pelos patologistas.

Contudo, quando uma mesma amostra é analisada por diferentes observadores podem ocorrer discordâncias na determinação do grau histológico (NORTHRUP et al., 2005; PINKZOWSKI et al., 2008). Por esta razão, Kiupel et al. (2011) propuseram uma classificação que divide o mastocitoma em baixo e alto grau de malignidade, que proporciona elevado nível de concordância para a graduação histológica da neoplasia.

Independentemente da classificação utilizada, o exame histopatológico tem influência direta na conduta terapêutica, que, por sua vez, depende do grau de diferenciação, intensidade de proliferação e envolvimento das margens cirúrgicas (LONDON \& THAMM, 2013).

\section{Tratamento}

Sempre que possível, a ressecção cirúrgica do mastocitoma é a modalidade de tratamento mais efetiva, desde que realizada com margens de segurança (FULSCHER et al., 2006). No entanto, a escolha da terapia depende principalmente do estadiamento clínico e do grau histológico do tumor (LONDON \& SEGUIN, 2003).

A cirurgia pode ser curativa, sobretudo nos casos de tumores bem diferenciados, mas os mastocitomas de grau II ou III podem exigir o tratamento medicamentoso. Nesses casos, a quimioterapia antineoplásica pode ser empregada com o objetivo de cito-redução ou como adjuvância. Fármacos comumente utilizados para o tratamento do mastocitoma em cães são a vimblastina, prednisona, ciclofosfamida e lomustina, com posologia variável, dependendo do protocolo terapêutico adotado (LONDON \& SEGUIN, 2003; WELLE et al., 2008; LONDON \& THAMM, 2013) (Tabela 2).

A utilização dos inibidores de receptores de tirosinaquinase é uma opção de tratamento para os tumores que apresentam mutação em c-KIT e, nesses casos, consiste em uma das terapias mais efetivas (LONDON, 2009; JARK et al., 2012). Esta nova classe de medicamentos, apesar de ter eficácia comprovada contra os mastocitomas, ainda está sob constante investigação para avaliação de seus efeitos benéficos e colaterais (BLACKWOOD et al., 2012, JARK et al., 2012). Toceranib (Palladia) e Masitinib (Masivet) são medicamentos de uso veterinário, incluídos em tal grupo cuja comercialização ainda não está aprovada no Brasil. Há evidências de que a sua utilização concomitante com a quimioterapia também pode ser benéfica para os pacientes com mastocitoma (BLACKWOOD et al., 2012; ROBAT et al., 2012).

\section{Prognóstico}

Fatores relacionados à apresentação clínica, tais como: localização, número de tumores e presença de ulceração podem influenciar o prognóstico. Os mastocitomas localizados no leito ungueal, escroto, prepúcio e focinho são os mais agressivos e proporcionam um tempo de sobrevida mais curto (GIEGER et al., 2003; THAMM et al., 2006; HILLMAN et al., 2010). De maneira oposta, Newman et al. (2007), demonstraram que os cães que

Tabela 2 - Protocolos de quimioterapia para o mastocitoma cutâneo em cães PREDNISONA E VIMBLASTINA (THAMM et al., 1999)

Prednisona: $2 \mathrm{mg} / \mathrm{Kg}$, por via oral, diariamente. Reduzir a dose após 30 dias. Suspender após 12 a 26 semanas.

Vimblastina: $2 \mathrm{mg} / \mathrm{m}^{2}$, por via intravenosa, semanalmente, totalizando quatro aplicações. Depois, administrar a cada duas semanas, totalizando quatro aplicações.

\section{PREDNISONA, VIMBLASTINA E CICLOFOSFAMIDA (CAMPS-PALAU et al., 2007)}

Prednisona: $1 \mathrm{mg} / \mathrm{Kg}$, por via oral, diariamente. Reduzir a dose após 30 dias. Suspender após 24 a 32 semanas.

Vimblastina: 2 a $2,2 \mathrm{mg} / \mathrm{m}^{2}$, por via intravenosa, a cada três semanas. Ciclofosfamida: 200 a $250 \mathrm{mg} / \mathrm{m}^{2}$, por via oral ou intravenosa, a cada três semanas. Iniciar sete dias após a vimblastina.

LOMUSTINA* (RASSNICK et al., 1999)

Lomustina: 70 a $90 \mathrm{mg} / \mathrm{m}^{2}$, a cada 21 dias.

VIMBLASTINA E LOMUSTINA* (COOPER et al., 2009)

Vimblastina: $2 \mathrm{mg} / \mathrm{m}^{2}$, por via intravenosa.

Lomustina: 60 a $70 \mathrm{mg} / \mathrm{m}^{2}$, por via oral.

Alternar os fármacos a cada duas semanas.

${ }^{*}$ A prednisona pode ser adicionada a estes protocolos 
apresentaram tumores localizados no tecido subcutâneo sobreviveram por mais tempo. Independentemente da localização, os tumores ulcerados apresentaram o pior prognóstico (MULLINS et al., 2006).

A influência do número de tumores sobre o prognóstico é controversa. Enquanto MULLINS et al., (2006) sugeriram não haver relação com o tempo de sobrevida, Furlani et al., (2008) associaram a presença de múltiplos nódulos com prognóstico desfavorável.

Um dos fatores prognósticos mais confiáveis para o mastocitomas caninos é o grau histológico (LONDON \& SEGUIN, 2003). Tumores de alto grau (KIUPEL et al., 2011) ou tumores de grau II e III (PATNAIK et al., 1984) apresentam pior prognóstico, pois estão relacionados a tempo de sobrevida mais curtos.

Padrões de expressão da proteína c-kit e do índice de proliferação pela proteína Ki-67 têm sido crescentemente determinados pela técnica de imuno-histoquímica e quando são associadas apresentam um valor prognóstico relevante. Cães com mastocitoma que apresentam mutação em c-KIT apresentam prognóstico desfavorável (ZEMKE et al., 2002), especificamente quando a marcação segue um padrão citoplasmático focal ou difuso (Webster et al., 2004). O Ki-67 é um indicador de proliferação celular e, assim como o c-KIT, está relacionado com tempo de sobrevida índice de metástase (WEBSTER et al., 2007; THOMPSON et al., 2011). Adicionalmente, a proliferação celular também pode ser avaliada pelo índice mitótico (ROMANSIK et al., 2007)..

\section{Considerações finais}

Apesar dos avanços obtidos na análise do diagnóstico e tratamento dos mastocitomas cutâneos dos cães, ainda é difícil o estabelecimento do prognóstico desta patologia, pois a sua apresentação clínica, o comportamento biológico e a resposta ao tratamento são muito variáveis.

\section{REFERÊNCIAS}

BLACKWOOD, L.; MURPHY, S.; BURACCO, P.; DE VOS, J.P.; DE FORNEL-THIBAUDS, P.; HIRSCHBERGER, J.; KESSLER, M.; PASTORS, J.; PONCE, F.; SAVARY-BATAILLE, K.; ARGYLE, D.J. European consensus document on mast cell tumours in dogs and cats. Veterinary and Comparative Oncology, v.10, n.3, p.1-29, 2012.

BOSTOCK, D.E. The prognosis following surgical removal of mastocytomas in dogs. Journal of Small Animal Practice, v.14, p.27-41,1973.

CAMPS-PALAU, M.A.; LEIBMAN, N.F.; ELMSLIE, R.; LANA, S.E.; PLAZA, S.; MCKNIGHT, J.A.; Risbon, R.; Bergman, P.J. Treatment of canine mast cell tumours with vinblastine, cyclophosphamide and prednisone: 35 cases (1997 - 2004). Veterinary and Comparative Oncology, v.5, n.3, p.156-167, 2007.

COOPER, M.; TSAI, X.; BENNETT, P. Combination CCNU and vinblastine chemotherapy for caninemast cell tumours: 57 cases. Veterinary and Comparative Oncology, v.7, n.3, p.196-206, 2009

DALECK, C.R.; ROCHA, N.S.; FURLANI, J.M.; CESAR, J.R.F. Mastocitoma. In: DALECK, C.R.; NARDI, A.B.; RODASKI, S. Oncologia em cães e gatos. São Paulo: Roca, 2009. p. 282-291.

DOBSON, J.M.; SCASE, T.J. Advances in the diagnoses and management of cutaneous mast cell tumours in dogs. Journal of Small Animal Practice, v.48, n.8, p.424-431, 2007.

FULSCHER, R.P.; LUDWIG, L.L.; BERGMAN, P.J.; NEWMAN, S.J.; SIMPSON, A.M.; PATNAIK, A.K. Evaluation of a two-centimeter lateral surgical margin for excision of grade I and grade II cutaneous mast cell tumors in dogs. Journal of the American Veterinary Medical Association, v.228, p.210-215, 2006.

FURLANI, J.M.; DALECK, C.R.; VICENTI, F.A.M.; DE NARDI, A.B.; PEREIRA, G.T.; SANTANA, A.E.; EURIDES, D.; SILVA, L.A.F. Mastocitoma canino: estudo retrospectivo. Ciência Animal Brasileira, v.9, p.242-250, 2008.

GIEGER, T.L.; THEON, A.P.; WERNER, J.A.; MCENTEE, M.C.; RASSNICK, K.M.; DECOCK, H.E. Biologic behavior and prognostic factors for mast cell tumors of the canine muzzle: 24 cases (1990-2001). Journal of Veterinary Internal Medicine, v.17, p.687-92, 2003.

HILLMAN, L.A., GARRETT, L.D., LORIMIER, L.P.; CHARNEY, S.C.; BORST, L.B.; FAN, T.M. Biological behavior of oral and perioral mast cell tumors in dogs: 44 cases (1996-2006). Journal of the American Veterinary Medical Association, v.237, p.936-942, 2010.

JARK, P.C.; MACHADO, L.H.A.; SAKATE, M.; CALAZANS, S.G.; CÁPUA, M.L.B.; TINUCCI-COSTA, M.; DE NARDI, A.B.; Inibidores de tirosina quinase no tratamento de mastocitomas cutâneos em cães - revisão. Clínica Veterinária (São Paulo), v. 99, p. 50-56, 2012.

KIUPEL, M.; WEBSTER, J.D.; MILLER, R.A.; KANEENE, J.B. Impact of tumour depth, tumour location and multiple synchronous masses on the prognosis of canine cutaneous mast cell tumours. Journal of Veterinary Medicine, series A, v.52, p.280-286, 2005.

KIUPEL, M.; WEBSTER, J.D.; BAILEY, K.L.; BEST, S.; DELAY, J.; DETRISAC, C.J.; FITZGERALD, S.D.; GAMBLE, D.; GINN, P.E.; GOLDSCHMIDT, M.H.; HENDRICK, M.J.; HOWERTH, E.W.; JANOVITZ, E.B.; LANGOHR, I.; LENZ, S.D.; LIPSCOMB, T.P.; MILLER, M.A.; MISDORP, W.; MOROFF, S.; MULLANEY, T.P.; NEYENS, I.; O'TOOLE, D.; RAMOS-VARA, J.; SCASE, T.J.; SCHULMAN, F.Y.; SLEDGE, D.; SMEDLEY, R.C.; SMITH, K.; SNYDER, P.W.; 61 SOUTHORN, E.; STEDMAN, N.L.; STEFICEK, B.A.; STROMBERG, P.C.; VALLI, V.E.; WEISBRODE, S.E.; YAGER, J.; HELLER, J.; MILLER, R. Proposal of a twotier histologic grading system for canine cutaneous mast cell tumors to more accurately predict biological behavior. Veterinary Pathology, v.48, p.147- 155, 2011.

LAUFER-AMORIM, R. Biomarcadores prognósticos em mastocitomas cutâneos caninos, avaliação em lâminas de arranjo de matriz tecidual (TMA). 2011. 61f. Tese (Livre Docente) - Faculdade de Medicina Veterinária e Zootecnia, Universidade Estadual Paulista, Botucatu. 
LAVALLE, G.; ARAUJO, R.; CARNEIRO, R.; PEREIRA, L. Punção aspirativa por agulha fina para diagnóstico de mastocitoma em cães. Arquivos Brasileiros de Medicina Veterinária e Zootecnia, v. 55, p. 500-502, 2003.

LONDON, C.A.; SEGUIN, B. Mast cell tumors in the dog. Veterinary Clinics of North America: Small Animal Practice, v.33, p. 473-489, 2003

LONDON, C.A. Tyrosine kinase inhibitors in veterinary medicine. Topics in Companion Animal Medicine, v. 24, p.106-112, 2009

LONDON, C.A.; THAMM, D.H.; VAIL, D.M. Mast cell tumors In: WITHROW, S.J., MAC EWEN, E.G. Small Animal Clinical Oncology, p.335 - 355, 2013

MULLINS, M.N.; DERNELL, W.S.; WITHROW, S.J.; EHRHART, E.J.; THAMM, D.H.; LANA, S.E. Evaluation of prognostic factors associated with outcome in dogs with multiple cutaneous mast cell tumors treated with surgery with and without adjuvant treatment: 54 cases (1998-2004). Journal of the American Veterinary Medicine Association, v. 228, p. 91-95, 2006.

MURPHY, S.; BREARLEY, M.J. Mast cell tumors. In: ARGYLE, D.J.; TUREK, M.M. BREARLEY, M.J. Decision Making in Small Animal Oncology. Singapore: Blackwell, 2008. p.147-158.

NEWMAN, S.J.; MRKONJICH, L.; WALKER, K.K.; ROHRBACH, B.W. Canine subcutaneous mast cell tumor: diagnosis and pronosis. Journal of Comparative Pathology, v.136, p.231-39, 2007.

NORTHRUP, N.C.; HOWERTH, E.W.; HARMON, B.G.; BROWN, C.A.; CARMICHEAL, K.P.; GARCIA A.P.; LATIMER, K.S.; MUNDAY, J.S.; RAKICH, P.M.; RICHEY, L.J.; STEDMAN, N.L.; GIEGER, T.L. Variation among pathologists in the histologic grading of canine cutaneous mast cell tumors with uniform use of a single grading reference. Journal of Veterinary Diagnostic Investigation, v.17, p.561-564, 2005.

PATNAIK, A.K.; EHLER, W.J.; MACEWEN, E.G. Canine cutaneous mast cell tumors: morphologic grading and survival time in 83 dogs. Veterinary Pathology, v.21, p.469474,1984

PINCZOWSKI, P.; TORRES-NETO, R.; FABRIS, V.E.; LAUFER-AMORIM, R. Mastocitoma cutâneo canino. Variação entre observadores na graduação histopatológica. Clínica Veterinária, v.77, p.76-8, 2008.

RASSNICK, K.M.; MOORE, A.S.; WILLIAMS, L.E.; LONDON, C.A.; KINTZER, P.P.; ENGLER, S.J.; COTTER, S.M. Treatment of canine mast cell tumors with CCNU (Lomustine). Journal of Veterinary Internal Medicine, v.13, p.601-605, 1999.

ROBAT, C.; LONDON, C.; BUNTING, L.; MCCARTAN, L.; STINGLE, N.; SELTING, K.; KURZMAN, I.; VAIL, D.M. Safety evaluation of combination vinblastine and toceranib phosphate (Palladia $囚$ ) in dogs: a phase I dose-finding study. Veterinary and Comparative Oncology, n.10, p.174-183, 2012
ROMANSIK, E.M.; REILLY, C.M.; KASS, P.H.; MOORE, P.F.; LONDON, C.A. Mitotic índex is predictive for survival for canine cutaneous mast cell tumors. Veterinary Pathology, v.44, p.335-41, 2007

SFILIGOI, G.; RASSNICK, K.M.; SCARLETT, J.M.; NORTHRUP, N.C.; GIEGER, T.L. Outcome of dogs with mast cell tumors in the dog inguinal or perineal region versus other cutaneous locations: 124 cases (1990-2001). Journal of American Veterinary Medical Association, v.226, p.1368-74, 2005.

THAMM, D.H.; MAULDIN, E.A.; VAIL, D.M. Prednisone and vinblastine chemotherapy for canine mast cell tumor-41 Cases (1992-1997). Journal of Veterinary Internal Medicine, v.13, p.491-497, 1999.

THAMM, D.H.; TUREK, M.M.; VAIL, D.M. Outcome and prognostic factors following adjuvant prednisone/vimblastine chemotherapy for high-risk canine mast cell tumour: 61 cases. Journal of Veterinary Medical Sciences, v.68, p.581-87, 2006

THOMPSON, J.J.; YAGER, J.A.; BEST, S.J.; PEARL, D.L.; COOMBER, B.L.; TORRES, R.N.; KIUPEL, M.; FOSTER, R.A. Canine subcutaneous mast cell tumours: cellular proliferation and KIT expression as prognostic indices. Veterinary Pathology, v. 48, n.1, p. 169-181, 2011.

VILLAMIL, J.A.; HENRY, C.J.; BRYAN, J.N.; ELLERSIECK, M.; SCHLTZ, L.; TYLER, J.W.; HAHN, A.W. Identification of the most common cutaneous neoplasms in dogs and evaluation of breed and age distributions for selected neoplasms. Journal of the American Veterinary Medical Association, v.239, p.960-965, 2011.

WHITE, C.R.; HOHENHAUS, A.E.; KELSEY, J.; PROCTER-GRAY, E. Cutaneous MCTs: associations with spay/neuter status, breed, body Size, and phylogenetic cluster. Journal of the American Animal Hospital Association, v. 47, p. 210-216, 2011.

WEBSTER, J.D.; KIUPEL, M.; KANEENE, J.B.; MILLER, R.; YUZBASIYAN-GURKAN, V. The use of KIT and tryptase expression patterns as prognostic tools for canine cutaneous mast cell tumors. Veterinary Pathology, v.41, p.371-377, 2004

WEBSTER, J.D.; YUZBASIYAN-GURKAN, V.; MILLER, R.A.; KANEENE, J.B., KIUPEL, M. Cellular proliferation in canine cutaneous mast cell tumors: associations with C-KIT and its role in prognostication. Veterinary Pathology, v.44, p.298-308, 2007.

WELLE, M. M.; BLEY, C. R.; RÜFENACHT, S.; HOWARD, J. Canine mast cell tumours: a review of the pathogenesis, clinical features, pathology and treatment. Veterinary Dermatology, v.19, p.321-339, 2008.

ZEMKE, D.; YAMINI, B; YUZBASIYAN-GURKAN, V. Characterization of an undifferentiated malignancy as a mast cell tumor using mutation analysis in the proto-oncogene C-KIT. Journal of Veterinary Diagnostic Investigation, v.13, p.341-345, 2001.

ZEMKE, D.; YAMINI, B; YUZBASIYAN-GURKAN, V. Mutations in the juxtamembrane domain of $c-K i t$ are associated with higher grade mast cell tumors in dogs. Veterinary Pathology, v.39, p.529-535, 2002. 